\title{
STRATEGI PENINGKATAN HUBUNGAN KERJASAMA PT. XYZ DENGAN MITRA LOGISTIK
}

\author{
Birawa Sudaryono \\ Program Studi S2 MM Wijawiyata Manajemen \\ Sekolah Tinggi Manajemen PPM \\ Sumartoyo \\ Sekolah Tinggi Manajemen PPM
}

\begin{abstract}
Penggunaan sistem outsourcing untuk menangani kegiatan bisnis pendukung perusahaan menjadi tren yang berkembang pesat saat ini. Penggunaan sistem ini memungkinkan perusahaan untuk berfokus pada inti bisnis mereka. Isu permasalahan yang terjadi terkait dengan kinerja carrier sebagai mitra logistik dalam memenuhi tugas pengiriman barang dari perusahaan penggunanya. Pada penelitian ini akan dibahas mengenai cara untuk meningkatkan kinerja carrier dengan pendekatan kolaborasi hubungan kerjasama rantai pasokan. Hasil analisis menunjukkan bahwa peningkatan kinerja carrier dapat dilakukan dengan menerapkan strategi peningkatan kerjasama dengan carrier. Penerapan strategi ini dilakukan kepada potensial carrier yang terpilih untuk memaksimalkan potensi yang dimilikinya.
\end{abstract}

Keywords:

outsourcing, kinerja, carrier, kolaborasi, strategi 


\section{PENDAHULUAN}

Sebagai perusahaan sales dan distribusi barang-barang konsumsi (FMCG) dengan skala nasional, PT XYZ mempunyai serangkaian keuntungan dan kelemahan dalam bisnis ini. Berdasarkan analisis kekuatan, kelemahan, peluang dan ancaman (SWOT), PT. XYZ mempunyai peluang untuk memperbesar jangkauan maupun volume penjualan terkait dengan peningkatan permintaan barang-barang konsumsi dalam negeri. Selain itu PT. XYZ mempunyai kekuatan dalam merespon kebutuhan pasar dengan baik, ini ditandai dengan meningkatnya pendapatan penjualan terutama ke luar Jawa.

Seiring dengan meningkatnya pendapatan maka semakin bertambah pula volume pengiriman barang ke cabangcabang penjualan PT. XYZ. Berdasarkan analisis SWOT, kelemahan utama PT. XYZ adalah ketergantungan perusahaan pada penyedia jasa pengiriman (carrier) sebagai mitra logistik yang menangani aktivitas distribusi barang ke gudang-gudang cabang dan sub cabang yang tersebar di seluruh wilayah Indonesia. Ketergantungan ini menimbulkan ancaman yang cukup besar bagi PT. XYZ karena PT. XYZ harus mengalokasikan pengeluaran transportasi yang lebih besar untuk membayar pelayanan mitra logistik dalam mendistribusikan barang-barang PT. XYZ.

Isu permasalahan yang terkait dengan penggunaan carrier pada perusahaan PT. XYZ adalah permasalahan performansi yang kurang maksimal dari masing-masing carrier yang digunakan. Berdasarkan analisis Kinerja Carrier diketahui bahwa ada dua faktor kinerja yang belum optimal yaitu ketepatan penjemputan barang dan keamanan pengiriman barang. Permasalahan ini terjadi karena saat ini PT. XYZ menitikberatkan pemakaian carrier yang bertarif murah dan mengesampingkan pelayanan yang ditawarkan masing-masing mitra logistik yang digunakan.

Penelitian pada paper ini akan membahas tentang strategi peningkatan hubungan kerjasama PT. XYZ dengan mitra logistik. Diharapkan dengan meningkatkan hubungan kerjasama dapat meningkatkan pula performansi mitra logistik dalam menangani pengiriman PT. XYZ.

\section{TINJAUAN TEORI DAN PENGEMBANGAN HIPOTESIS}

\subsection{Rantai Pasokan}

Rantai pasokan adalah suatu sistem logistik yang kompleks dimana material pokok dirubah menjadi barang jadi dan didistribusikan ke konsumen akhir (Gianpaolo et al, 2004). Council of Logistics Management mendefinisikan logistik sebagai bagian dari proses rantai pasokan yang meliputi perencanaan, pengimplementasian dan pengelolaan secara efektif dan efisien pergerakan barang, jasa dan informasi dari titik sumber barang hingga titik konsumsi konsumen (CLM, 1991).

Menurut Bowersox (2002), logistik adalah aktivitas kombinasi perusahaan yang meliputi pengelolaan pesanan, inventori, transportasi, gudang, penanganan material dan pengemasan produk yang terintegrasi pada suatu jaringan.

Menurut Edward Frazelle (2002) logistik supply chain adalah aliran material, informasi dan uang diantara korporasi (antar workstation, antar fasilitas, antar korporat 
dan intrachain). Sedangkan menurut Alan dan Remko (2008) logistik adalah sebuah aktivitas yang mengatur dua aliran utama, pertama aliran material secara fisik dari supplier ke toko melalui pusat distribusi. Kedua, yaitu aliran informasi permintaan dari end-customer ke purchasing dan ke supplier dan data suplai dari supplier ke retail, sehingga aliran material dapat dikontrol dan direncanakan secara akurat. Aliran rantai pasokan dapat dilihat pada deskripsi Gambar 1.

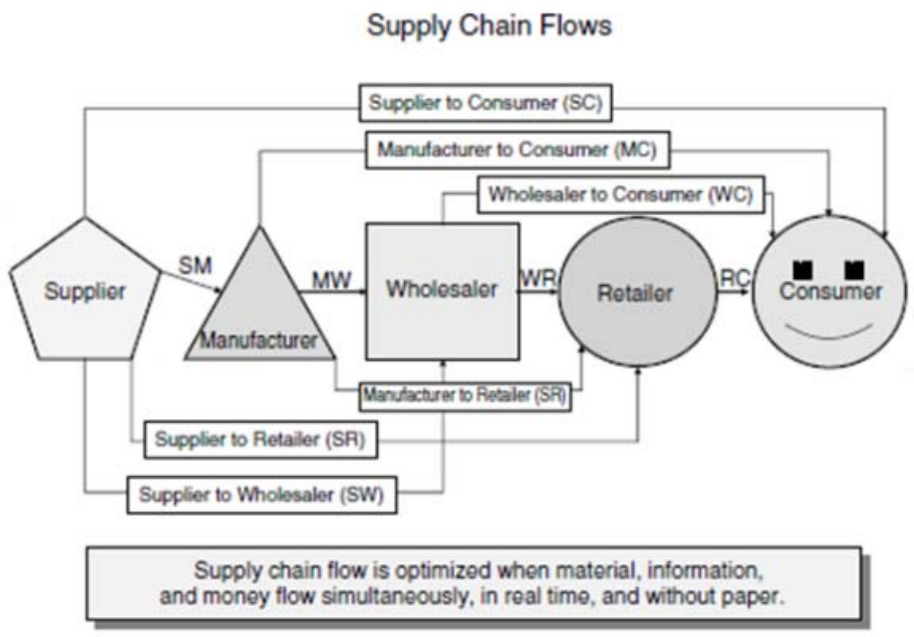

sumber : Frazelle (2002)

Gambar 1.

Aliran Rantai Pasokan

\subsection{Sourcing}

Sourcing adalah sekumpulan proses bisnis yang dibutuhkan untuk untuk membeli barang atau servis (Chopra et al, 2007). Chopra mendefinisikan dua keputusan penting dalam melakukan fungsi supplychain, yakni outsource atau in-house.

Outsourcing dapat didefinisikan sebagai pemakaian jasa spesialisasi pihak eksternal untuk menjalankan dan mengatur aktivitas atau fungsi pendukung bisnis inti (Alan et al, 2007). Penggunaan outsourcing bertujuan untuk meningkatkan fleksibilitas suatu perusahaan (Ostring, 2004).

Perusahaan eksternal yang bertindak sebagai penyedia jasa logistik dikenal dengan sebutan third-party logistic providers (3PL) (Bowesox, 2002). aktivitas bisnis Berdasarkan studi 3PL yang dilakukan oleh Langley aktivitas logistik yang biasanya di- outsource adalah transportasi dan pergudangan (Alan, 2007).

Beberapa pengoperasian di bidang logistics outsourcing digambarkan dalam sebuah diagram outsourcing continuum. Gambar 2 mendemonstrasikan kemungkinan pengimplementasian outsourcing (Alan, 2007).

Ada lima langkah pembentukan sourcing yang didefinisikan Chopra (2007), yakni pertama, Supplier scoring and assesment adalah proses penilaian performa supplier. Supplier harus dibandingkan berdasarkan dampak surplus rantai pasokan dan total biaya. Faktor scoring diantaranya adalah lead time, reliability, quality, design capability.

Kedua, Supplier selection yaitu tahap pemilihan supplier yang tepat. Tahap ini menggunakan inputan dari tahap supplier 
scoring. Kemudian diikuti dengan negosiasi kontrak. Kontrak kerja yang baik harus didesain agar menguntungkan dua belah pihak.

Ketiga, Design collaboration adalah tahap dimana supplier dan manufacture bekerja sama dalam mendesain produk. Keterbukaan informasi dan komunikasi yang lancar antara kedua belah pihak merupakan faktor yang penting dalam mencapai tujuan kolaborasi.

Keempat, Procurement merupakan proses dimana supplier mengirimkan produk ke pembeli sesuai pesanan. Tujuan tahap ini adalah mengirimkan produk sesuai pesanan dan tepat waktu dengan total biaya yang rendah sedapat mungkin.

Langkah terakhir adalah Sourcing planning and analysis. Tahap ini adalah tahapan untuk mengevaluasi kinerja supplier yang sudah dipilih secara keseluruhan, baik dari segi performa hingga total biaya. Gambar 3. menunjukkan tahapan pembentukan sourcing.

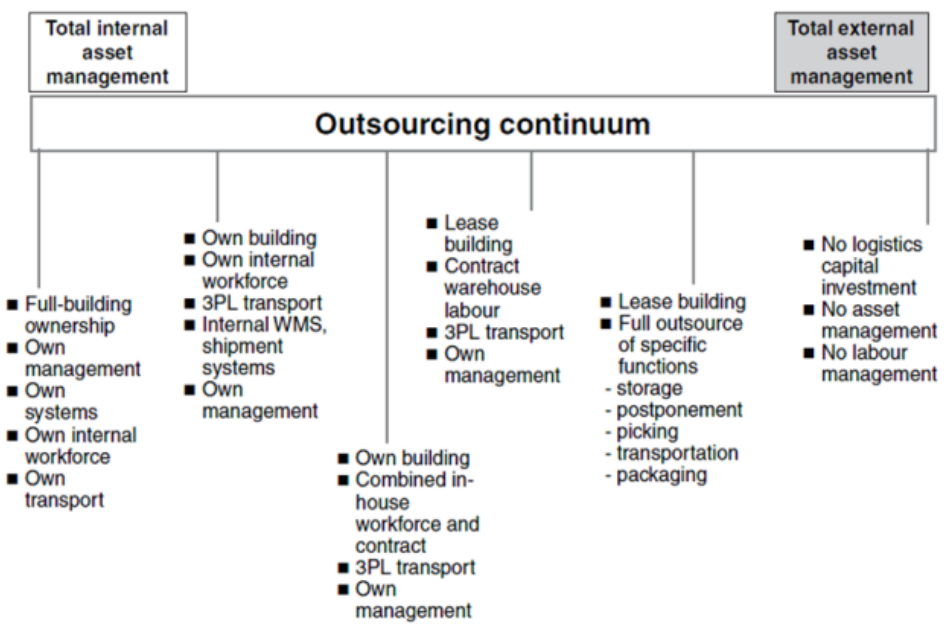

sumber : Alan et.el. (2007)

Gambar 2.

Outsourcing Continuum

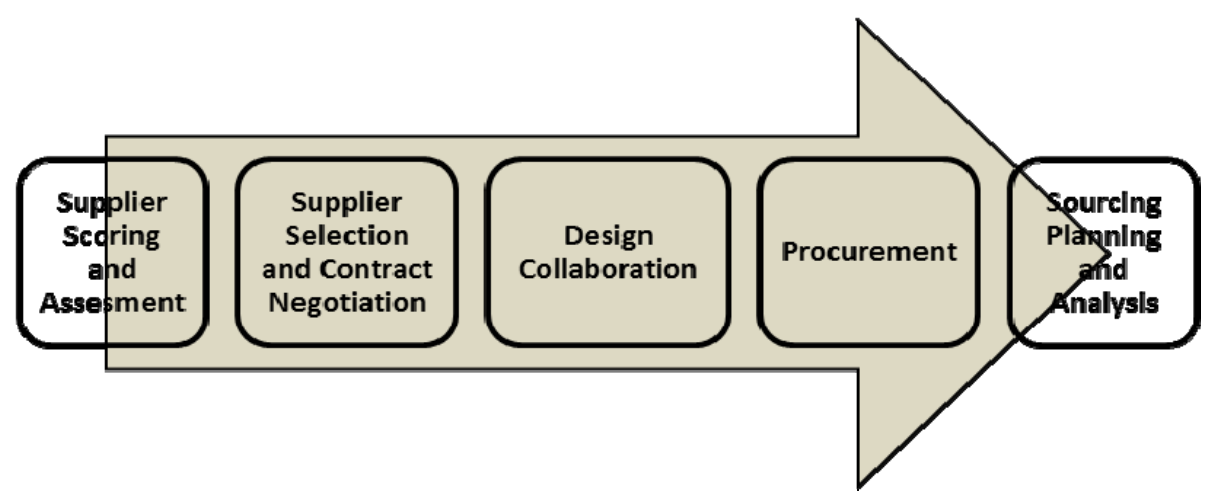

sumber : Chopra (2002)

Gambar 3.

Tahapan Sourcing

2.3 Supply Chain Collaboration 
Definisi kolaborasi bervariasi diantara para peneliti. Menurut Cohen kolaborasi adalah kerjasama antar perusahaan didalam rantai suplai untuk mencapai sasaran bersama dengan berbagi ide, informasi, pengetahuan, risiko dan penghargaan (Cohen dan Roussel, 2005). Cohen mengatakan bahwa hati dari kolaborasi adalah informasi dan kesuksesan atau kegagalan dari hubungan kolaborasi tergantung kejelasan sasaran bersama.

Menurut Richards, kolaborasi merupakan aktivitas bekerja bersama-sama untuk membawa sumber daya kedalam hubungan yang dibutuhkan untuk mencapai keefektifan operasi yang bersinergi dengan strategi dan tujuan dari organisasi yang bekerjasama sehingga menghasilkan keuntungan bersama (Richards, 2004).

John Gattorna berpendapat bahwa kolaborasi adalah bekerja dengan seseorang untuk membuat atau menciptakan sesuatu dimana organisasi tidak dapat melakukannya sendiri (Gattorna, 2009). Kolaborasi yang dimaksudkan disini adalah hubungan bisnis yang menghasilkan solusi win-win yang membawa keuntungan bagi dua belah pihak. Walaupun definisi kolaborasi berbeda-beda antara satu dengan yang lain, namun inti dari kolaborasi adalah bekerjasama untuk meraih keuntungan bersama.

Kolaborasi yang nyata dapat terjadi di dalam hubungan rantai pasokan jika kepercayaan antar pihak yang bersangkutanterjalin kokoh. Ada dua cara untuk membangun kepercayaan yakni pertama, demonstrasi reliabilitas operasi yang konsisten dan sesuai janji serta ekpektasi dari masing-masing rekan kerja. Kedua, kemauan untuk berbagi informasi secara lengkap sehingga hubungan yang terjalin lebih efektif (Bowersox, 2002).

Beberapa faktor yang menjadi penghalang dalam mewujudkan kesuksesan kolaborasi adalah (Alan dan Remko, 2008):
1. Adanya penyalahgunaan kekuatan yang dimiliki pemain rantai suplai terhadap rekan kerja lainnya.

2. Adanya pandangan negatif terhadap arti dari kerjasama, seperti investasi kepada rekan kerja sehingga menambah beban pengeluaran.

3. Sementara buyer menghargai kepercayaan, komitmen dan reliabilitas rekan kerja, maka mereka dapat bertindak opportunistic dan mencari keuntungan dari pengeluaran rekan kerjanya.

4. Buyer seringkali hanya fokus terhadap kepentingan perusahaan sendiri dibanding kepentingan rekan kerja, walaupun dalam jangka panjang dapat menghasilkan keuntungan bersama.

5. Harga merupakan atribut kunci dalam pertimbangan memilih supplier.

\subsection{Analytic Hierarchy Process}

Analytic Hierarchy Process (AHP) adalah teori pengukuran melalui pairwise comparisan dan bergantung pada pendapat dari para ahli mengenai permasalahan yang diangkat untuk mendapatkan skala prioritas. (Saaty, 2008). Skala ini digunakan untuk mengukur aspek-aspek intangibles berdasarkan seberapa kali pentingnya faktor yang satu dengan yang lain.

Metode AHP didasarkan oleh kemampuan manusia terhadap penggunaan informasi dan pengalaman untuk memperkirakan tingkat relativitas melalui pair comparison. AHP memungkinkan penggunanya untuk memecah permasalahan menjadi bagian-bagian.

Ada empat langkah yang dideskripsikan oleh Saaty untuk mengambil keputusan, yakni :

1. Mendefinisikan permasalahan dan menentukan apa yang akan dicari.

2. Membuat hirarki keputusan dari level atas ke level bawah. Struktur dimulai dari tujuan pengambilan keputusan, kemudian 
penentuan elemen sasaran dari berbagai perspektif hingga elemen paling akhir.

3. Membuat kumpulan matriks perbandingan (pairwise comparison) untuk setiap elemen yang dibuat di hirarki.

4. Membuat prioritas untuk setiap elemen pada setiap level. Prioritas ini digunakan sebagai pembobotan elemen yang dibandingkan satu dengan yang lain.

Untuk mebuat perbandingan maka Saaty menggunakan bantuan angka 1-9 yang merepresentasikan hubungan antar faktor yang dibandingkan, dapat dilihat pada Tabel 1.

Tabel 1.

Skala Prioritas

\begin{tabular}{|c|c|c|}
\hline $\begin{array}{l}\text { Intensity of } \\
\text { Importance }\end{array}$ & Definition & Explanation \\
\hline 1 & Equal importance & Two activities contribute equally to the objective \\
\hline 2 & Weak & \\
\hline 3 & Moderate importance & $\begin{array}{l}\text { Experience and judgement slightly favour one } \\
\text { activity over another }\end{array}$ \\
\hline 4 & Moderate plus & \\
\hline 5 & Strong importance & $\begin{array}{l}\text { Experience and judgment strongly favour one } \\
\text { activity over another }\end{array}$ \\
\hline 6 & Strong plus & \\
\hline 7 & $\begin{array}{l}\text { Very strong or demonstrated } \\
\text { importance }\end{array}$ & $\begin{array}{l}\text { An activity is favoured very strongly over another; } \\
\text { its dominance demonstrated in practice }\end{array}$ \\
\hline 8 & Very, very strong & \\
\hline 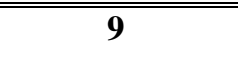 & Extreme importance & $\begin{array}{l}\text { The evidence favouring one activity over another } \\
\text { is of the highest possible order of affirmation }\end{array}$ \\
\hline $\begin{array}{l}\text { Reciprocals of } \\
\text { above }\end{array}$ & $\begin{array}{l}\text { if activity / has one of the above } \\
\text { nonzero numbers assigned to it } \\
\text { when compared with activity } j \text {, } \\
\text { then } j \text { has the reciprocal value } \\
\text { when compared with } i\end{array}$ & A reasonable assumption \\
\hline Rationals & Ratios arising from the scale & $\begin{array}{l}\text { If consistency were to be forced by obtaining } n \\
\text { numerical values to span the matrix }\end{array}$ \\
\hline
\end{tabular}

sumber : Saaty dan Vargas (1994)

\section{METODOLOGI PENELITIAN}

Metode yang digunakan untuk mendapatkan data primer dan sekunder sebagai data analisis dan pendukung penulisan ini adalah sebagai berikut:

1. Data primer, diperoleh dengan melakukan observasi terhadap area penelitian dan wawancara dengan beberapa pihak yang berhubungan langsung dengan pengiriman dan transportasi.
2. Data sekunder, diperoleh dari dokumendokumen internal perusahaan terkait dengan pengiriman dan transportasi, serta literatur, buku maupun jurnal riset lain.

Dalam penyusunan tulisan ini digunakan kerangka analisi yang berfungsi sebagai acuan dan arahan penelitian sehingga tidak menyimpang dari pokok permasalahan yang dibahas. Gambar 4. menggambarkan kerangka analisis yang digunakan. 


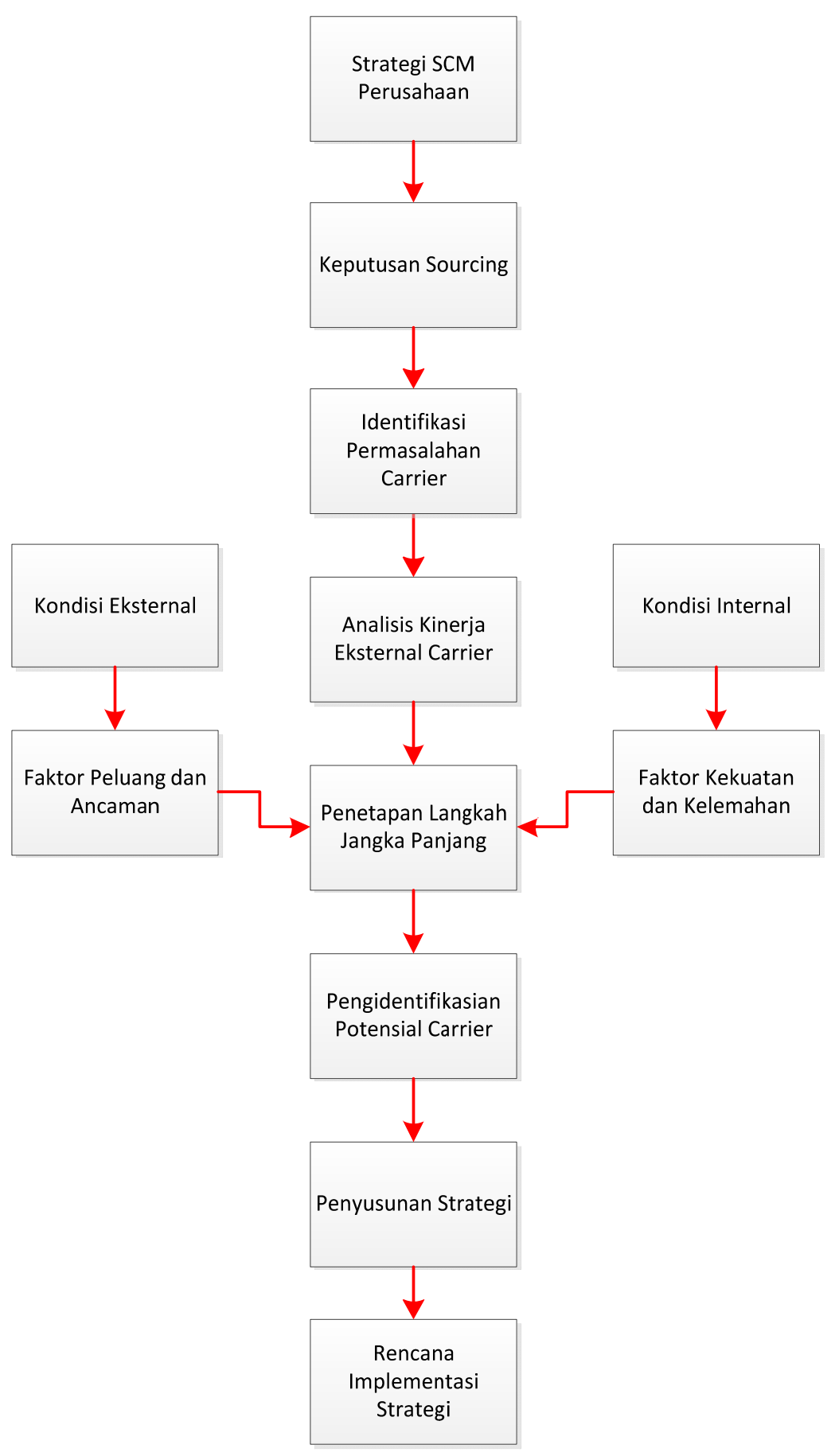

Gambar 4.

Kerangka Analisis 


\section{PEMBAHASAN}

Pembahasan terdiri dari tiga analisis pokok, yakni analisis kinerja carrier, analisis SWOT dan analisis potensial carrier.

\subsection{Analisis Kinerja Carrier(AKC)}

Analisis kinerja digunakan untuk mengetahui letak permasalahan kinerja operasional carrier dalam menangani pengiriman. Analisis kinerja mempertimbangkan tiga faktor performa, yakni on time pickup, transit time dan keamanan carrier.

\subsubsection{Analisis kinerja On Time Pickup (OTP)}

Prosentase nilai OTP carrier eksternal yang menangani jalur pengiriman laut dapat dilihat pada Gambar 5. Berdasarkan hasil analisis, tingkat reliabilitas carrier dalam menangani penjemputan barang adalah sebesar $46 \%$. Hal ini berarti aktualisasi penjemputan yang sesuai dengan jadwal perencanaan (hit) kurang dari 50\%.

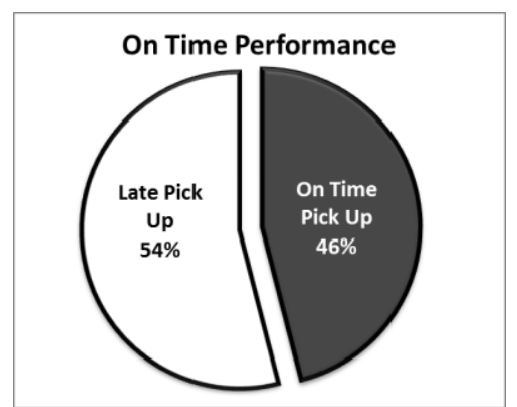

Gambar 5.

Performa Transit Time

Tetapi apabila diteliti lebih lanjut performa OTP setiap carrier terhadap beban pengirimannya diketahui bahwa salah satu carriermempunyai nilai ketepatan diatas rata-rata 46\%. Gambar 6 menunjukkan performa OTP per carrier.

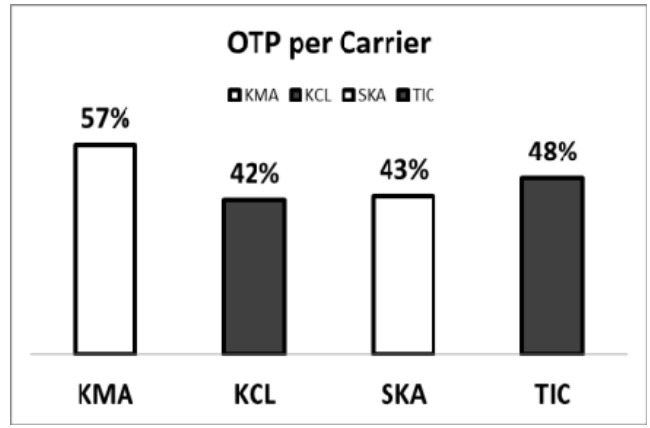

Gambar 6.

Performa OTP per Carrier

Keterlambatan ini disebabkan oleh dua faktor utama, pertama adalah, hambatan dalam perjalanan, seperti lokasi pool truk yang jauh dari gudang PT. XYZ, kondisi jalan raya yang tidak menentu, macet dan kecelakaan. Kedua adalah faktor kondisi truk 
yang tidak lolos pemeriksaan sebelum proses muat barang. Faktor kedua ini menyebabkan truk ditolak dan PT. XYZ harus menunggu datangnya truk pengganti, yang kemungkinan akan menggeser jadwal muat.

\subsubsection{Analisis kinerja Transit Time (TT)}

Nilai kinerja eksternal carrier jalur laut dilihat dari waktu transit seperti terdapat pada Gambar 7. Hasil analisis menunjukkan sebanyak $45 \%$ pengiriman via laut tiba di tempat tujuan dalam batas waktu standar lead time pengiriman yang disusun PT. XYZ. Hal ini berarti rata-rata tingkat reliabilitas waktu transit carrier dalam menangani pengiriman kurang dari 50\%.

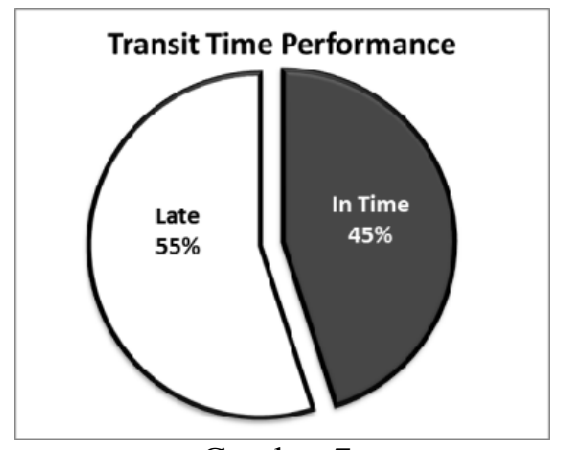

Gambar 7.

Performa Transit Time

Tetapi jika diteliti lebih lanjut performa masing-masing carrier dalam menangani pengiriman yang dibebankan kepada carrier diketahui bahwa carrier SKA dan TIC mempunyai nilai ketepatan diatas rata-rata, yakni masing-masing 59\% dan $50 \%$. Gambar 8 menunjukkan grafik performa waktu transit setiap carrier.

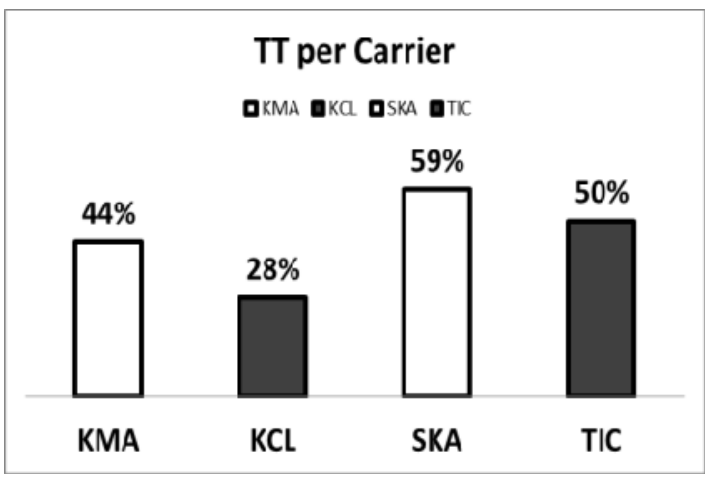

Gambar 8 .

Performa TT per Carrier

Waktu transit yang lama ini disebabkan oleh dua faktor utama. Faktor pertama yakni kecelakaan saat diperjalanan, keterlambatan keberangkatan kapal dan kemungkinan gangguan pada mesin kapal. Faktor kedua adalah kondisi gudang penerima yang penuh sehingga muatan dalam kontainer harus ditunda 
pembongkarannya. Faktor gudang penuh dapat terjadi karena adanya sistem push produk dari prinsipal ke PT. XYZ.

\subsubsection{Analisis Keamanan Carrier}

Prosentase kejadian klaim barang ke asuransi dapat dilihat pada Gambar 9. Hasil analisis menunjukkan bahwa klaim karena disebabkan oleh kontainer bocor sebesar $88 \%$ meliputi tujuh kejadian dan $12 \%$ sisanya disebabkan oleh kecelakaan meliputi satu kecelakaan.

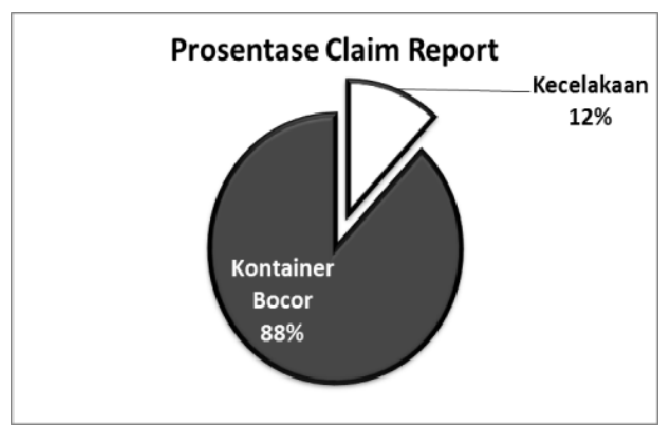

Gambar 9.

Prosentase Klaim

Kejadian kontainer bocor, dialami oleh carrier KCL dengan lima kejadian, diikuti KMA dan SKA masing-masing satu kejadian. Angka ini membuktikan bahwa tingkat keamanan transporter KCL lebih kecil dibandingkan dengan KMA dan SKA. Sedangkan satu kejadian kecelakaan truk dialami oleh SKA. Dari data diketahui bahwa KCL mempunyai tingkat keamanan yang kurang terkontrol dibandingkan KMA dan SKA.

Permasalahan kontainer bocor merupakan tanggung jawab carrier berkaitan dengan keamanan fasilitas yang digunakan dan ditawarkan. Akibat dari permasalahan ini adalah muatan yaitu produk menjadi cacat atau rusak sehingga tidak dapat dijual sebagaimana mestinya. Ini merupakan kerugian bagi pemilik barang karena kehilangan kesempatan untuk menjual produk ke pasar dan memenuhi permintaan konsumen. Kerugian ini dapat berakibat konsumen berpindah ke produk lain karena tidak tersedianya produk yang diinginkan saat dicari.

\subsection{Analisis SWOT}

Analisis SWOT dimulai dengan mengidentifikasi faktor-faktor yang eksternal dan internal perusahaan yang mempengaruhi pemilihan langkah jangka panjang. Faktorfaktor eksternal kemudian dikembangkan menjadi daftar peluang dan ancaman. Peluang merupakan kesempatan yang dapat diambil perusahaan sedangkan ancaman adalah kejadian yang mungkin dapat membahayakan kegiatan bisnis perusahaan. Sedangkan faktor-faktor internal dikembangkan menjadi daftar kekuatan dan kelemahan yang dimiliki perusahaan. Tabel 2. dan Tabel 3. mendeskripsikan daftar peluang, ancaman, kekuatan dan kelemahan. 
Tabel 2.

Peluang dan Ancaman

\begin{tabular}{||l||l||}
\hline \multicolumn{1}{|c||}{ OPPORTUNITY } & \multicolumn{1}{|c||}{ THREAT } \\
\hline \hline Daya beli masyarakat meningkat. & $\begin{array}{l}\text { Adanya biaya tambahan yang harus dikeluarkan } \\
\text { perusahaan dalam pendistribusian barang. }\end{array}$ \\
\hline $\begin{array}{l}\text { Pelayanan yang diberikan oleh perusahaan logistik } \\
\text { semakin baik. }\end{array}$ & $\begin{array}{l}\text { Terjadinya kecelakaan atau hambatan dalam } \\
\text { perjalanan pengiriman barang }\end{array}$ \\
\hline $\begin{array}{l}\text { Konsumsi masyarakat terhadap kebutuhan pangan } \\
\text { semakin besar. }\end{array}$ & $\begin{array}{l}\text { Alokasi biaya transportasi yang dikeluarkan } \\
\text { perusahaan semakin besar. }\end{array}$ \\
\hline \hline Skala pembelian barang oleh retailer semakin besar. & \\
\hline $\begin{array}{l}\text { Peran pemerintah dalam memajukan kompetensi } \\
\text { logistik semakin besar. }\end{array}$ & \\
\hline \hline
\end{tabular}

Tabel 3.

Kekuatan dan Kelemahan

\begin{tabular}{||l||l||}
\hline \multicolumn{1}{|c|}{ STRENGTH } & \multicolumn{1}{c|}{ WEAKNESS } \\
\hline Dapat merespon permintaan pelanggan sangat baik. & $\begin{array}{l}\text { Cabang dan sub cabang makin besar dan makin susah } \\
\text { susah dikontrol }\end{array}$ \\
\hline \hline Perputaran barang di PT. XYZ meningkat. & etergantungan pada carrieruntuk menangani distribusi. \\
\hline $\begin{array}{l}\text { Perputaran uang terus meningkat dan barang yang } \\
\text { ditangani PT. XYZ terserap baik di pasar. }\end{array}$ & $\begin{array}{l}\text { Penggunaan outsourcing yang berbeda-beda dalam } \\
\text { mengirim ke luar jawa. }\end{array}$ \\
\hline \hline $\begin{array}{l}\text { PT. XYZ mampu menarik konsumen dari luar } \\
\text { jawa. }\end{array}$ & \\
\hline
\end{tabular}

Proses pembuatan strategi dilakukan dengan memadukan antara kekuatan dan kelemahan yang dimilki perusahaan dengan peluang dan ancaman yang ada untuk melihat kemungkinan-kemungkinan langkah yang dapat diambil perusahaan. Proses ini dideskripsikan pada Tabel 4.

Tabel 4.

SWOT Matriks

\begin{tabular}{|c|c|c|}
\hline & $\mathbf{S}$ & $\mathbf{W}$ \\
\hline $\mathbf{O}$ & $\begin{array}{l}\text { - Menambah jumlah konsumen }(\mathrm{S} 1,3 \\
\text {,O1,3,4) } \\
\text { - Menambah area distribusi (S4 ,O5) }\end{array}$ & $\begin{array}{l}\text { - Mencari carrier dengan cakupan pengiriman yang } \\
\text { luas }(\mathrm{W} 1,3, \mathrm{O} 2) \\
\text { - Mencari carrier dengan tarif murah }(\mathrm{W} 2,3, \mathrm{O} 2) \\
\text { - Mengembangkan sistem in-house untuk menangani } \\
\text { pengiriman ke luar jawa }(\mathrm{W} 3, \mathrm{O} 2)\end{array}$ \\
\hline $\mathbf{T}$ & $\begin{array}{l}\text { - Meningkatkan utilisasi transport }(\mathrm{S} 2,3 \text {, } \\
\text { T1,3) } \\
\text { - Meningkatkan penjualan produk yang } \\
\text { high value }(\mathrm{S} 3,4, \mathrm{~T} 1,3)\end{array}$ & $\begin{array}{l}\text { - Meningkatkan hubungan kerjasama dengan carrier } \\
\text { aktif saat ini (W1,3,T1,2,3) } \\
\text { - Memaksimalkan potensi carrier yang dipakai (W3 } \\
\text {,T1,3) }\end{array}$ \\
\hline
\end{tabular}


Berdasarkan matriks SWOT, ada dua langkah jangka panjang yang dapat diimplementasikan di PT. XYZ terkait dengan hubungan kerjasama dengan carrier. Pertama adalah mencari carrier baru untuk melayani pengiriman. Kedua adalah meningkatkan kerjasama dengan carrier yang sudah dipakai.

Langkah pertama merupakan langkah termudah yang dapat dilakukan oleh perusahaan untuk mengatasi kinerja carrier yang tidak maksimal yakni mencari carrier baru. Tetapi langkah ini akan memunculkan permasalahan baru, seperti permasalahan kinerja atau pelayanan yang kurang baik karena perusahaan belum tahu pasti karakteristik dari calon carrier yang baru ini. Selain itu perusahaan harus memulai dari awal tahapan pembentukan outsourcing, yakni assesment dan scoring serta melakukan tahapan kontrak dan negosiasi terhadap calon carrier yang membutuhkan waktu tidak sebentar.

Oleh karena itu langkah kedua merupakan langkah yang tepat diimplementasikan perusahaan. Hal ini dimungkinkan karena perusahaan sudah menjalin hubungan kerjasama cukup lama sehingga mempunyai track record kinerja carrier tersebut. Selain itu perusahaan tidak memerlukan waktu untuk melakukan tahapan awal outsourcing.

\subsection{Analisis Potensial Carrier(APC)}

Analisis potensial carrier ditujukan untuk mengidentifikasi potensial carrier sebagai calon strategic partner. Pemilihan potensial carrier menggunakan bantuan Analytic Hierarchy Process (AHP) sebagai alat analisis.

\subsubsection{Hirarki Persoalan}

Kriteria-kriteria yang dipergunakan diambil dari literature review dengan topik faktor-faktor yang mempengaruhi pemilihan carrier. Tidak semua faktor dalam literatur dimasukkan sebagai kriteria pemilihan. Faktor-faktor yang dipilih disesuaikan dengan pendapat dari pengambil keputusan. Hal ini dilakukan karena hanya beberapa faktor yang menjadi pertimbangan pengambil keputusan dalam mengidentifikasi potensial carrier yang sudah dipakai oleh perusahaan.

Dari hasil wawancara ada lima kriteria utama dalam menentukan potensial yakni tarif carrier (rate), ketersediaan carrier (availability), kehandalan carrier (reliability), keamanan carrier (safety) dan kemudahan pendapatan informasi (easy of information). Dalam penyusunan hirarki unsur tarif tidak diikutsertakan dan akan dilakukan perhitungan tersendiri. Hal ini dilakukan untuk memisahkan faktor keuntungan (benefit) yang didapat dari carrier dengan tarif (rate) yang ditawarkan carrier. Selain itu pemisahan ini bertujuan agar pendapat dari pengambil keputusan tidak terpengaruh oleh faktor tarif murah yang ditawarkan carrier. Hirarki pemilihan Carrier terdapat pada Gambar 10. 


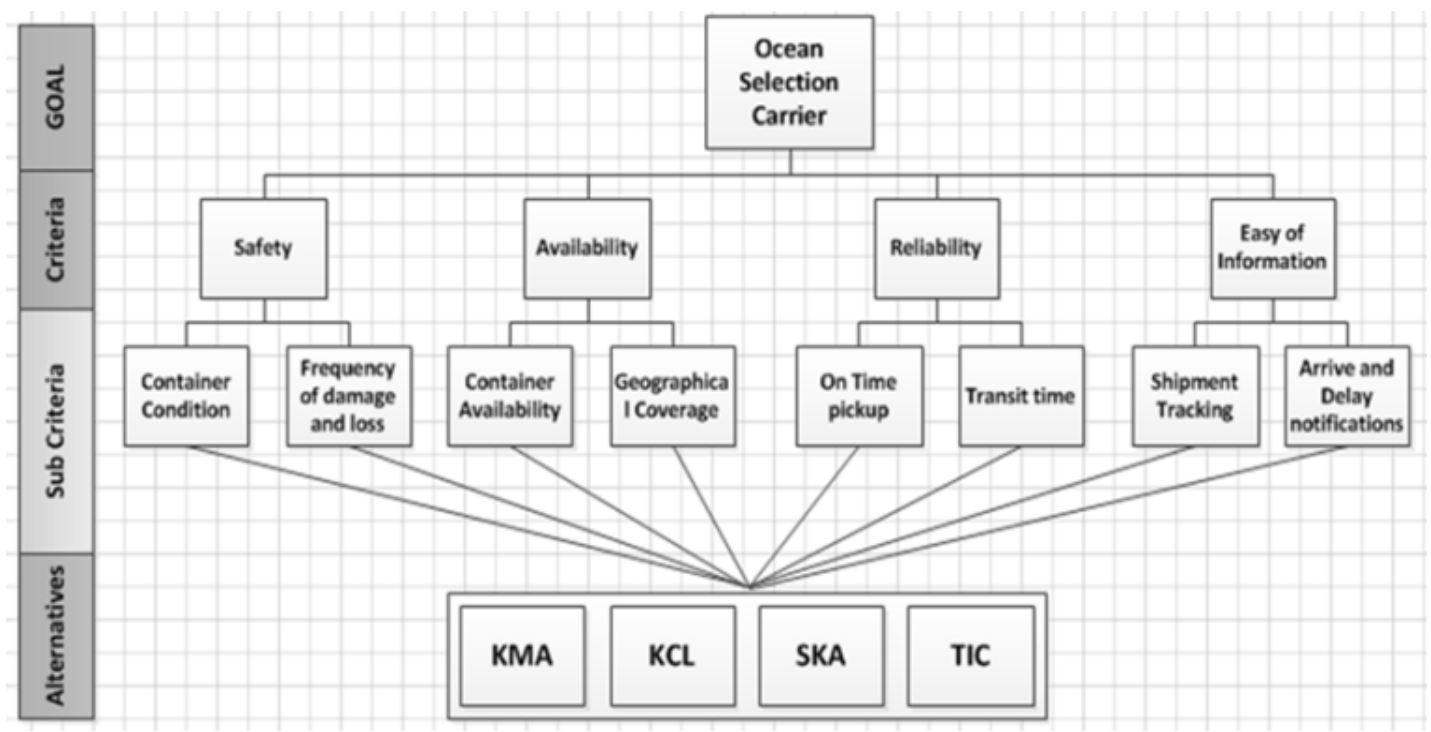

Gambar 10.

Hirarki Pemilihan Carrier

\subsubsection{Identifikasi Potensial Carrier}

Identifikasi potensial carrier merupakan langkah lanjutan dari penyusunan hirarki persoalan.Pembobotan kritera dilakukan dengan menggunakan bantuan perangkat lunak expert choice 11 . Pembobotan ini dilakukan dengan melakukan pairwise comparison kepada masing-masing kriteria, dan dibandingkan berdasarkan tingkat kepentingannya. Metode pairwise comparison yang digunakan adalah graphical pairwise comparison.

Dari hasil perhitungan, diketahui bahwa kriteria availability merupakan kriteria terpenting yang menjadi pertimbangan utama dalam mengidentifikasi potensial carrier dengan nilai bobot sebesar 0,426 . Diikuti dengan reliability $(0,314)$, safety $(0,153)$ dan easy of information $(0,107)$. Dari empat kriteria utama tersebut di bagi menjadi beberapa sub kriteria. Hasil perhitungan juga menunjukkan bahwa tingkat konsistensi rasio sebesar 0,03 . Hal ini membuktikan bahwa pairwise comparison yang dilakukan dapat dikatakan konsisten, karena berada di bawah rasio konsistensi (CR) yang diperbolehkan dalam AHP yakni $\mathrm{CR} \leq 0,1$.Detail mengenai bobot prioritas dapat dilihat pada Gambar 11. 


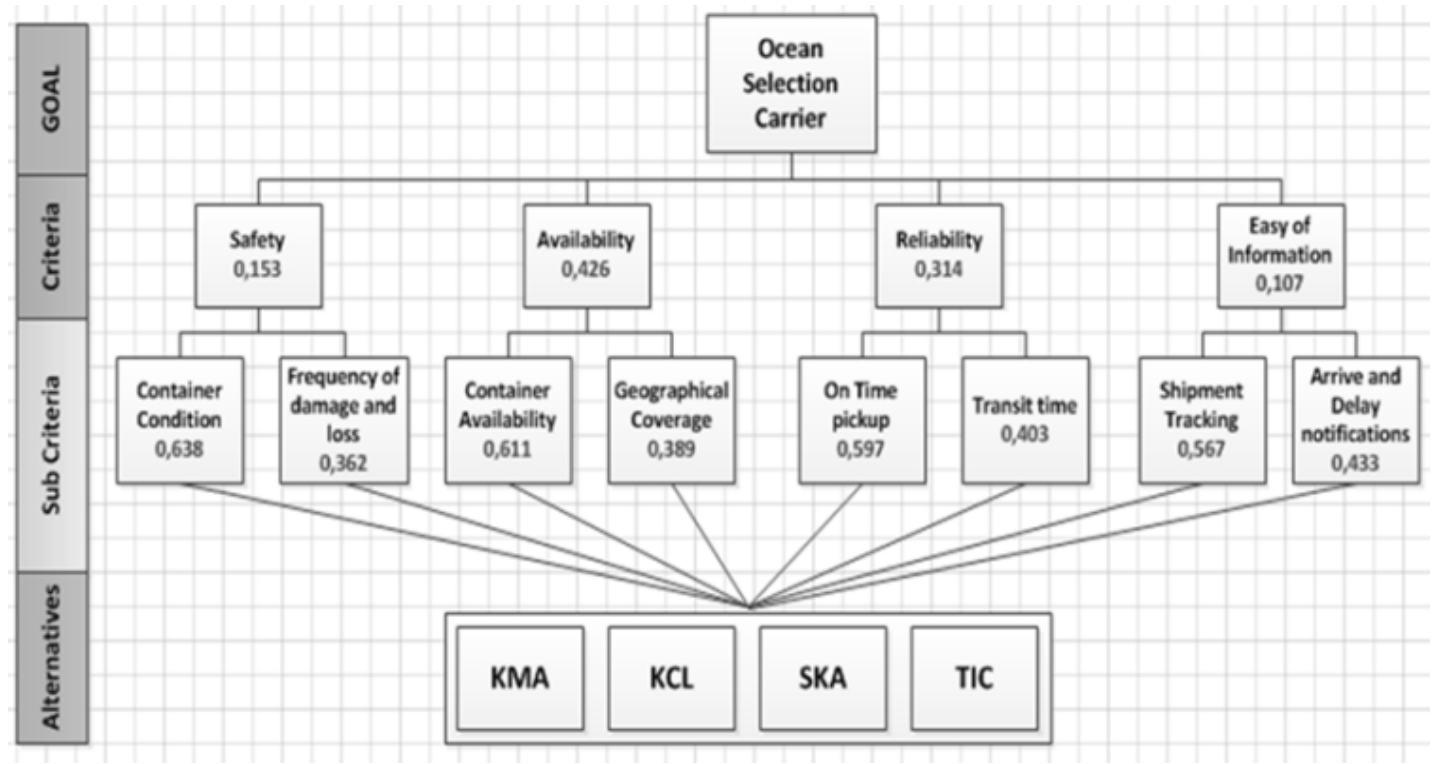

Gambar 11.

Bobot Kriteria Berdasarkan Tingkat Kepentingan

Langkah selanjutnya untuk yang sudah dibobotkan. Hasil sintesis dapat mengidentifikasi potensial carrier adalah dengan melakukan sintesis terhadap hirarki dilihat pada Gambar 12.

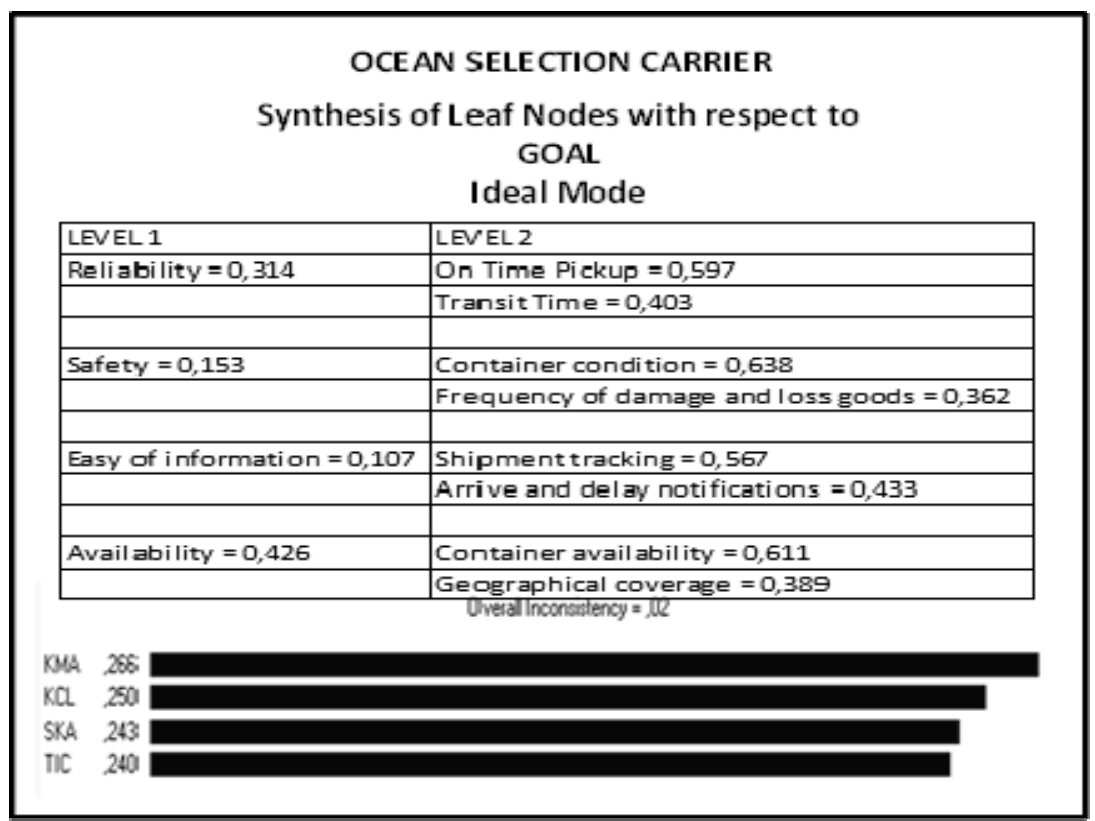

Gambar 12.

Hasil Sintesis 
Berdasarkan hasil sintesis diketahui bahwa KMA berada di peringkat pertama karena dilihat dari segi performa reliability, safety dan easy of information yang ditawarkan, rata-rata lebih unggul dari ketiga carrier lainnya. Hal ini berarti KMA dinilai mampu memberikan pelayanan yang lebih baik bila dibandingkan dengan KCL, SKA dan TIC.

Tabel 5.

Hasil Analisis Sensitivitas Kinerja

\begin{tabular}{|c||c|r|r|r|}
\hline & \multicolumn{1}{|c|}{ Cost } & Normalize Cost & \multicolumn{1}{c|}{ Benefit } & Benefit-cost Ratio \\
\hline \hline KMA & Rp 9.822.222,00 & 0,2575 & 0,266 & 1,033 \\
\hline \hline KCL & Rp 9.611.111,00 & 0,2520 & 0,250 & 0,992 \\
\hline \hline SKA & Rp 9.327.778,00 & 0,2446 & 0,243 & 0,993 \\
\hline \hline TIC & Rp 9.377.338,00 & 0,2459 & 0,240 & 0,976 \\
\hline \hline Total & $\operatorname{Rp} 38.138 .889,00$ & & & \\
\hline \hline
\end{tabular}

Dari hasil analisis sensitivitas kinerja (Tabel 5.), secara rata-rata nilai KMA lebih baik dibanding KCL, SKA dan TIC. KMA unggul dalam hal reliability, safety dan easy of information. Saat dilakukan skenario perubahan tingkat kepentingan kriteria, hasil analisis tetap menunjukkan bahwa KMA terpilih sebagai potensial carrier. Hal ini menandakan bahwa KMA merupakan kandidat yang kuat. Perubahan tingkat kepentingan tidak membawa dampak besar pada hasil carrier yang terpilih. KMA terbukti lebih superior dibandingkan KCL, SKA dan TIC dalam hal performa. Gambar 13. menggambarkan hasil sensitivitas kinerja.

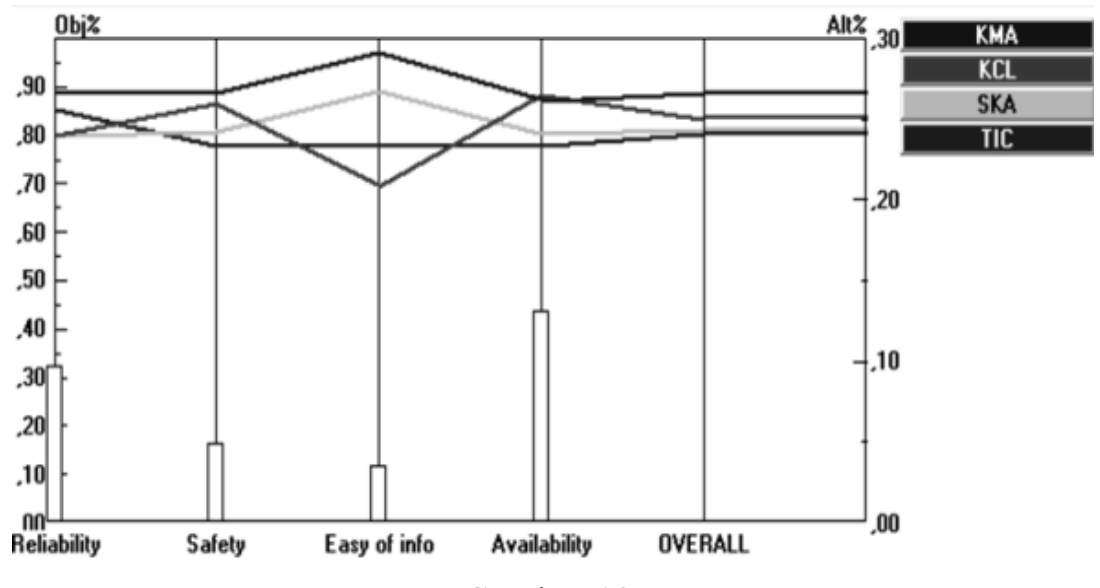

Gambar 13.

Hasil Sensitivitas Kinerja

Dari hasil analisis membuktikan bahwa perubahan moderat pada prioritas kriteria tidak akan berdampak besar terhadap potensial carrier yang terpilih. Oleh karena itu dapat disimpulkan bahwa hasil pemilihan tidak terlalu sensitif terhadap perubahan prioritas kriteria. 


\subsubsection{Perhitungan Rate-Benefit (RB)}

Perhitungan RB ditujukan untuk mengetahui rasio antara keuntungan yang diberikan dengan tarif yang ditawarkan masing-masing carrier.

Dari hasil perhitungan rate-benefit, susunan peringkat potensial carrier dari peringkat pertama adalah KMA, SKA, KCL dan TIC. Dapat dilihat bahwa KMA mempunyai rasio tertinggi dibanding ketiga carrier lainnya. Rasio ini menandakan bahwa perbandingan antara pelayanan yang diberikan dengan harga yang harus dibayar adalah sebanding. Walaupun harga rata-rata yang ditawarkan KMA lebih mahal sedikit dari ketiga carrier lainnya, KMA mampu memberikan kompensasi dalam bentuk pelayanan terbaik yang diberikan. Ini membuktikan bahwa KMA merupakan kandidat kuat potensial carrier karena mampu menawarkan tarif yang kompetitif tetapi tidak mengorbankan pelayanan yang ditawarkan.

\section{FORMULASI STRATEGI}

Untuk mengatasi permasalahan kinerja carrier sebagai mitra logistik yang tidak maksimal dapat dilakukan dengan menerapkan strategi kerjasama guna menumbuhkan saling pengertian dan komitmen yang sesuai harapan dua belah pihak, baik PT. XYZ. Strategi ini dinamakan strategi BMW (Gambar 14.).

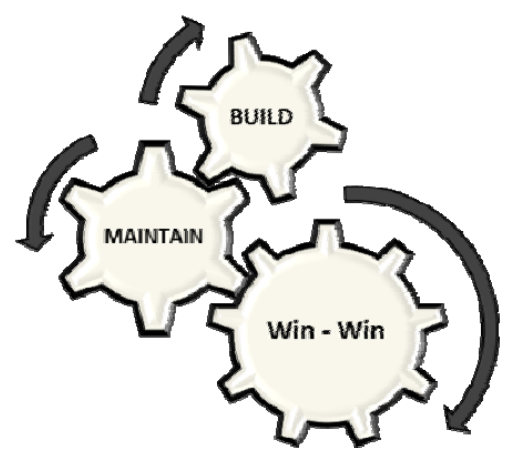

Gambar 14.

Strategi BMW

\section{KESIMPULAN}

Kesimpulan yang didapat dari penelitian ini yaitu:

1. Berdasarkan hasil analisis kinerja carrier diketahui bahwa rata-rata kinerja carrier jalur laut kurang reliabel, dilihat dari parameter on time pickup, transit time dan keamanan carrier.

2. Berdasarkan hasil analisis SWOT, cara yang dapat dilakukan PT. XYZ. untuk meningkatkan kinerja carrier adalah dengan meningkatkan hubungan kerjasama sehingga dapat memaksimalkan potensi yang dimiliki oleh carrier untuk skala jangka panjang.

3. Berdasarkan hasil analisis potensial carrier diidentifikasi bahwa KMA merupakan kandidat strategic partner bagi PT. XYZ. KMA mempunyai rata-rata performa yang lebih baik diantara KCL, SKA dan TIC. Selain itu KMA mampu memberikan tarif yang kompetitif tanpa mengesampingkan pelayanan yang diberikan. 


\section{DAFTAR PUSTAKA}

Bowersox, Donald J., David J. Closs dan M. Bixby Cooper. 2002.Supply Chain Logistics Management. New York: McGraw-Hill.

Chopra, Sunil dan Peter Meindl. 2007. Supply Chain Management: Strategy, Planning, and Operation. New York: Prentice Hall.

Cohen, Shoshanah and Joseph Roussel. 2005. Strategic Supply Chain Management: Five Disciplines for Top Performance. New York: McGraw-Hill.

Frazelle, Edward. 2002. Supply Chain Strategy. New York: McGraw-Hill.

Ghiani, Gianpaolo, Gilbert Laporte dan Roberto Musmanno. 2004. Introducion to Logistics Systems Planning and Control. England: John Wiley \& Sons, Ltd.

Harrison, Alan dan Remko Van Hoek. 2008. Logistics Management and Strategy: Competing through the supply chain. 3rd. Ed. Inggris: Prentice Hall.

Kersten, Prof. Dr. Wolfgang, Jan Koch dan Philipp Hohrath. 2004. Motivation for the outsourcing of complex logistics services. Hamburg School of Logistics.

Ostring, Pirkko. 2004. Profit - Focused Supplier Management. New York: AMACOM.

Saaty, L. Thomas. 2008. Decision Making With The Analytic Hierarchy Process. USA: Int. J. Services Sciences, Vol. 1, No. 1. Pittsburgh. 